\title{
Accountability in the Flipped Classroom: Student-Generated Pre-Lecture Concept Reflections
}

\section{Dr. Brittany B. Nelson-Cheeseman, University of St. Thomas}

Brittany Nelson-Cheeseman is an Assistant Professor in the School of Engineering at the University of St. Thomas in St. Paul, MN. She received her B.S. in Materials Science and Engineering from the University of Wisconsin - Madison, and her M.S. and Ph.D. in Materials Science and Engineering with a Designated Emphasis in Nanoscale Science and Technology from the University of California - Berkeley. She was also a post-doctoral researcher at Argonne National Lab in the Materials Science Division, working in the Center for Nanoscale Materials.

Kate Laura Steuer, University of St. Thomas 


\title{
Accountability in the Flipped Classroom: Student-Generated Pre-Lecture Concept Reflections
}

\begin{abstract}
When instructors first flip their classroom, many quickly come to the stark realization that they must employ some mechanism to hold students accountable for coming to class prepared. Often this ends up taking the form of a daily quiz on the out-of-class preparatory material. While this typically achieves the intended goal of extrinsically motivating the students to do their prelecture preparation, these quizzes bring their own challenges, such as student resentment, test anxiety, and dealing with student absences or sickness.

This paper presents an additional assessment mechanism, student-generated pre-lecture Concept Reflections (CRs), to be paired with a daily quiz to address many of the challenges commonly encountered with daily quizzes. First, the CR setup is presented, including student examples. Next, 441 student-generated CRs and a student survey are analyzed in a variety of ways to better understand how the students engage with the CR format.

Not only are the challenges inherent to daily quizzes virtually eliminated by the complementary use of CRs, but a host of additional benefits emerge for the students' learning. These benefits can be categorized under three main areas: stimulating intrinsic motivation and curiosity, enhancing cognition and memory, and developing metacognition and self-regulated learning. Finally, as an added side benefit, the instructor reaps a plethora of new analogies and examples to share with the class and future classes to aid understanding and retention of course concepts.
\end{abstract}

\section{Introduction}

While the flipped classroom has been shown to have myriad positive benefits, many have pointed out the necessity to promote student accountability in order for the Flipped Classroom technique to work successfully. ${ }^{1,2,3}$ Promoting student accountability can take various forms, but most often this is achieved through a Readiness Assessment Test (RAT). This is a short assessment of student preparation prior to the regular class activities, and often takes the form of an online or in-class quiz. ${ }^{4}$

Individual RATs have five main benefits: (1) they signal important vocab and concepts to the student; (2) they reinforce course material in a student's memory through forced recall; (3) they provide feedback to a student on their basic understanding of the material, (4) they provide an opportunity for a student to ask pointed questions, and instructors to practice "Just-in-Time" Teaching, ${ }^{5}$ and (5) they motivate a student to adequately prepare before class - not just by going through the motions of reading or watching the preparatory material, but also by micro-studying the material so they will begin to remember it when they need to recall it for the RAT.

While students generally understand the need for RAT activities and overwhelmingly recognize their helpfulness, administering RATs is not without challenges. The most common challenges 
include underlying student resentment, student test anxiety, and the inconvenience of dealing with student absence or sickness. ${ }^{6}$ In addition to these evident challenges of RATs, they also limit creative ways to retain learning. Methods to hold student's accountable for their learning readiness should more fully embrace the diverse ways in which students begin to construct their understanding of course content.

This paper presents on an integrated system of readiness assessment, whereby student-generated pre-lecture Concept Reflections (CRs) are paired with traditional instructor-generated RATs. In this paper, Concept Reflections are characterized as a short online response piece written by students that relates to the new material and is motivated by an analogy, revelation, photo, video, or article. Including these optional CRs, which are more open-ended and student driven, mitigates many of the challenges commonly encountered by schemes set up solely around instructor-generated RATs, and unlocks additional benefits to student learning.

\section{Methodology}

The data reported in this paper draws from two semesters of an upper-level undergraduate Introduction to Materials class (Spring 2015 (S15): N=25; Fall 2015 (F15): N=32) meeting three times per week. The class is primarily composed of Mechanical Engineering students, who are required to take the course for their degree, while a handful of students take the course as an elective (3 Chemistry, 1 Electrical Engineering/Physics.)

The format of the course is a flipped learning model, in which the students are given 4 to 65 minute instructor-generated videos on the lecture content before class. Although aligned textbook readings are also noted for those that prefer that method of preparation, the vast majority of students self-report that they only watch the videos to prepare for lecture. For the first 5-10 min of each 65 min class period, the students are quizzed, first, individually and, then, in groups on their ability to remember and understand of the content of the videos. This is meant to test the lowest levels of Bloom's Taxonomy. The rest of class time is spent practicing applying, analyzing, and evaluating the material, which is meant to develop the higher levels of Bloom's taxonomy.

While the daily individual quiz points ( 3 pts/day) count towards their course grade, the students are able to ensure those quiz points by completing CRs online via the learning management system (LMS) before class time. Because the CRs are meant to motivate readiness for the class period, students are not able to garner points for those submitted after the class period have begun. A timestamp is created when the CR is posted, thus ensuring a method to assess compliance with the timed deadline. One satisfactory CR counts for 1 point; thus, by submitting three complete CRs online before class begins, a student can ensure that they will receive all of the individual quiz points for that day. In other words, the students have six chances $(3 \mathrm{CR}$ pts + 3 quiz pts) to receive the three readiness assessment points for the day. To further clarify, students may only receive three total points, meaning a student completing three CRs and scoring three points on the quiz will still only receive a total of three points- $100 \%$ of the individual readiness points for that day. This is meant to give those students who have trouble with the quizzes another mechanism to earn the quiz points as long as they are willing to put in 
the extra effort to demonstrate their engagement with the lecture material. Posting CRs is entirely optional for the students.

The assignment prompt posted on the LMS for the CRs is shown below. Five formats are described. Note that for the analysis of this paper the last item is split into two distinct formats based on whether the item is an article or video.

\section{Concept Reflection Student Blog \\ CONTRIBUTE **4-8 SENTENCES** FOR ONE OF THE FOLLOWING: (1 PT EACH)}

- Concept Analogies: Choose a complex concept from the reading or videos. Explain the concept using an analogy to a simplistic concept that would be familiar to your peers. Be sure to explicitly (though concisely) explain how the two inter-relate, or what commonalities the two share.

- Materials Revelations: Choose a new concept from the assigned reading or videos. Select a common materials property or phenomenon (known to the layman) that connects this concept to real world experiences. Using vocabulary from the reading or videos, explain how and why the concept you've chosen gives rise to this common materials property or phenomenon.

- Materials "Instagram": Take an Intragram (photo) of a material that relates to a concept from the assigned reading or videos. Upload the photo to the blog, and describe the important aspects of the photo. What is the material specifically? What application is the material being used for? What properties are important? How does the material achieve these properties?

- Article/YouTube Video: Find an article or YouTube video that involves a new concept from the assigned reading or videos. Describe the new concept from the reading or videos, and explain how the article or video explains and/or links to this concept.

For the second semester, in addition to this prompt, a handful of satisfactory example CRs were posted at the beginning of the semester in order to model the instructor's expectations and demonstrate the postings of prior students. The online medium is a shared class blog page through the LMS. All students are able to see each other's posts and comment on them.

To grade the CRs, the instructor briefly reads through the posts to ensure they meet the minimum standards outlined in the assignment prompt. If a post meets the minimum standards, the instructor awards the student a readiness point for the given lecture. If the post does not meet the minimum standards and it is the student's first offense, the instructor makes a comment on the student's post as to what aspects they are missing in their post and does not award a readiness point. The student is welcome to repost their CR for re-grading as long as it is posted before class begins. For subsequent offenses, the instructor merely does not award credit for the posted unsatisfactory concept reflection. Whenever possible, the instructor reviews the posts before class time and mentions them during class time when related concepts are discussed. If a post is of high impact and there is time, the instructor shares the content item (e.g. YouTube video) with the class during class time, indicating the student who posted it. 
The following data was collected to analyze the CR technique: 441 student-generated CRs were reviewed. Student-generated examples of each CR format were selected. The number of satisfactory CRs submitted by each student for a given lecture was tabulated and compared to the student's daily quiz score for that lecture, as well as their subsequent compiled readiness score for that lecture. All submitted CRs were also coded by format type, time submitted before lecture, associated daily quiz score, and deviation from the average quiz score for that lecture. A survey was also given to the most recent class to elicit their feedback and self-reported data on the Concept Reflection technique.

\section{Results and Discussion}

In order for the reader to more fully grasp the format of a CR, a student-generated example of each CR format is listed below in Figures 1-5. Many submitted CRs mention the pre-class videos and the student's interest in learning more about related subjects. The sample CRs below demonstrate the student's increased intrinsic motivation and curiosity to further explore topic related to pre-class videos.

Analogy example:

Concept Analogy: Interatomic Bonding

Posted by $\Omega$ Student A February 3, 2015 6:31:09 AM

For the three main classes of a interatomic bonds, ionic, covalent and metallic, an analogy I think of is kids (atoms) in kindergarten and their toys (electrons). Ionic bonds are like when two kids are playing together and one kid decides he wants all the toys to play with, leaving none for other! Thus the metallic anion with the electrons taken from nonmetal cation is like the kid with all the toys. However, some kids in kindergartenknow how to share their toys! When two kids share their toys this is like a covalent bond sharing electrons. Now there can be different degrees of covalent bonds. When there is a difference in electronegativity, a polar covalent bond forms. A more electronegative atom is like when one kid still shares his or her toys, but likes to take more than his or her share of toys. A less electronegative atom is like the other kid who is really nice and gives away a lot of his or her toys. Finally metallic bonding is often described as a "sea of electrons." The electrons from the metal atoms can flow freely between all the atoms in the bond, not just between two atoms like in ionic and covalent bonding. This like when a kindergarten class has toys that the whole class shares, like a kickball or a jungle gym and the toys are used by all the kids together.

Figure 1: Example of a student submitted CR in the form of an analogy. 
Materials Revelation example:

\title{
Phosphorescence...In Your Backpack!
}

\author{
Posted by $\bigcap$ Student B April 17, 2015 9:44:29 AM
}

Phosphorescence was one of the long list of luminescence phenomena listed in the video. I would bet that you actually have phosphorescent material on your person everytime you walk into engineering. The buttons on our clickers are made of the same material that makes up childhood glow in the dark toys. If you cup your hands around the button, they glow a light green color. I would imagine this was designed so students could use these in darkened lecture halls. It is likely that the material in our buttons is either zinc sulfide or strontium aluminumate.

Quantum mechanically, phosphorescecne occurs because the electron that is excited is excited into a state through which only a "forbidden transition" would take it back down to its ground state. I put forbidden in quotes because the emission of light you do see is all the proof you need that the electron does relax and emit. The forbiddeness of the triplet-singlet transitions just result in a longer period of time for relaxation.

Figure 2: Example of a student submitted CR in the form of a revelation.

Instagram example:

Viscoelastic Silicone Rubber

Posted by $\cap$ Student C October 16, 2015 10:59:47AM

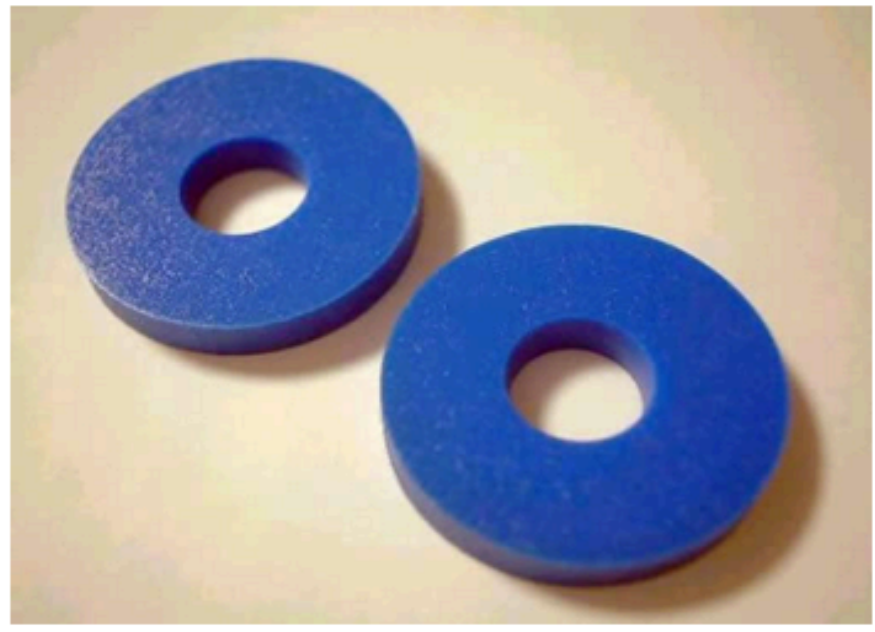

This material is known as viscoelastic silicone rubber. What makes it so special is that it has a stiffness that depends on time. When a change occurs to the silicone fast such as a hammer impact the rubber is stiff and resilient acting like a solid. However when things happen in a slower fashion such as a finger being pushed into it, it appears soft and flexible. Another key property is that if you leave it alone it always returns to its original shape. Applications for this are things like helmets or body armor due to the fact that it's flexing over time but if say a bullet strikes it, it will be resilient. These time dependent properties are possible because of the silicon rubbers crosslinks. Some are permanent which give it the stiffness and others are temporary thus the flexibility.

Figure 3: Example of a student submitted CR in the form of an Instagram. 
Article example:

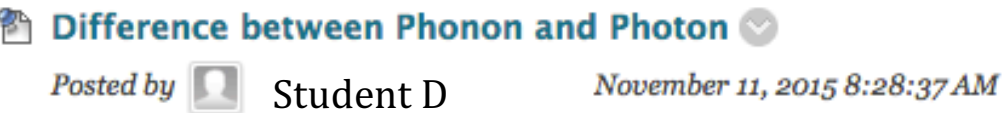

Here's a quick article explaining the difference of a phonon and photon. This article gives you more a physics background, but it helps with defining each of the terms. By understanding the difference of a phonon and photon, it can clarify the two very similar terms. This relates to our lecture with heat capacity.

A phonon is:

- a mode of oscillation that happens in the lattice structures

- A mode of vibration, which is not a wave or a particle

- bonds between atoms and inter-atomic bonds are elastic which causes the atoms and molecules to oscillate

A photon is:

- a form of energy

- is considered a particle and a wave (which you can physically observe)

- it's a particle in a "packet" of energy

http://www.differencebetween.com/difference-between-photon-and-vs-phonon/

Figure 4: Example of a student submitted $C R$ in the form of an article.

YouTube example:

\section{Super Cooled Beer}

Posted by $\Omega$ Student E February 22, 2015 10:03:43 PM

https://www.youtube.com/watch?v=WOfURJg-KOA

See the link for a video of supercooled beer. As the lecture videos discussed, materials need to have a nucleation site into to start the phase transition from liquid to solid. These nucleation sites can be a "seed crystal" of the material, impurities or a rough surface. In order to super cool a liquid such as beer or your preferred beverage of choice, you place the bottle into the freezer for somewhere between $30 \mathrm{~min}$ to 3 hours. You want it to be cold but not yet solid. In this state, the liquid has dropped just below the freezing point but since the bottle is so smooth there aren't any rough surfaces for ice crystals of the beer to form so the nucleation rate is too low for any solid to form. Yet the grow rate is high, so when you take the bottle and smack it against the counter you give it enough energy to induce nucleation and the liquid quickly solidifies. I thought it was really cool in this video how you could really see all the different nucleation sites as the beer was solidifying!

Figure 5: Example of a student submitted CR in the form of a video. 


\section{Student Motivations Towards Concept Reflections}

Overall, $79 \%$ of the students complete at least one concept reflection by the end of the semester. This demonstrates that in general students find them useful for some purpose over the course of the semester.

To explore the student motivations for completing CRs, Figure 6(a) demonstrates student responses on why they do choose to complete the CRs. The most popular self-reported reason is to pad their quiz score. This reasoning likely correlates with a decrease in student resentment for the quizzes. Although student resentment of the quizzes was not explicitly surveyed in the students, student comments from the mid-term and final course evaluations indicate that students appreciate this additional opportunity to display their preparation for class.

The second greatest reason students complete CRs is to better understand the material. This demonstrates a clear link to students identifying what aspects of the material they do not understand or are confused about and self-directing themselves to better understand that aspect of the material. This is a key tenet of metacognition - the ability to know what one doesn't know or understand. This encourages students to take control and self-regulate their learning.

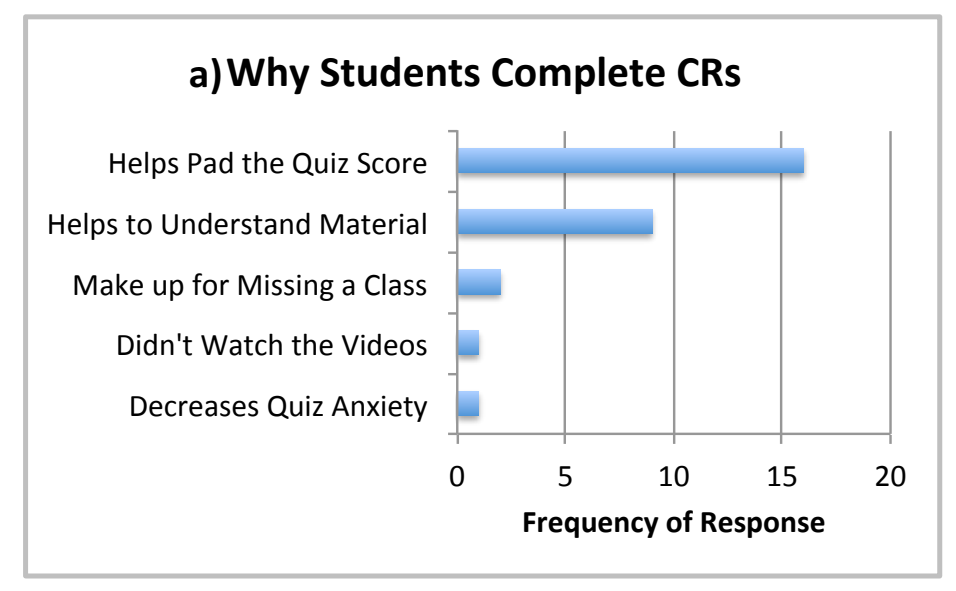

\section{b)Why Students Choose Not To Do CRs}

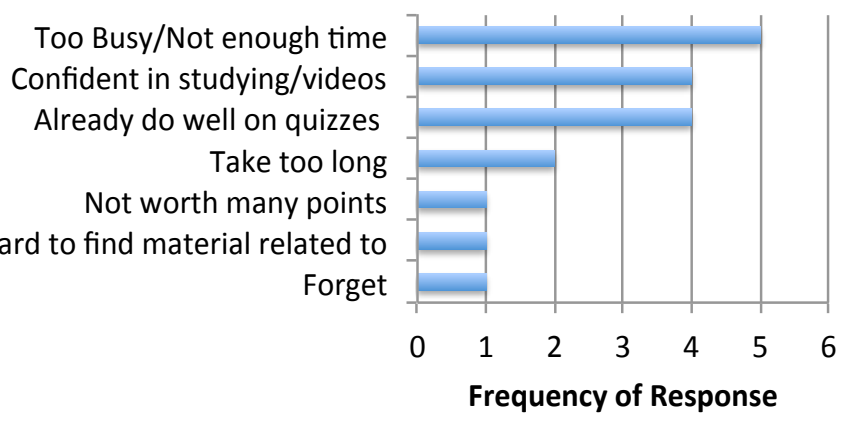

Figure 6 - Student survey results for (a) why students complete CRs, and (b) why student choose not to complete CRs. 
Figure 6(b) demonstrates student responses on why they choose not to complete the CRs for a given lecture. The most common reasons are time constraints and that they generally already do well enough on the quizzes with their own studying techniques. Likely the students who are already satisfied with their quiz performance have minimal resentment of the RATs. As instructors know well, classes are made up of a wide variety of learners, and it is often difficult to satisfy all of them with a single mode of assessment. In this respect, it is not necessarily a negative that much of the class does not feel the need to post CRs for every lecture. The fact that at some time or another throughout the semester the majority of students do find reasons to complete them supports their use in the class.
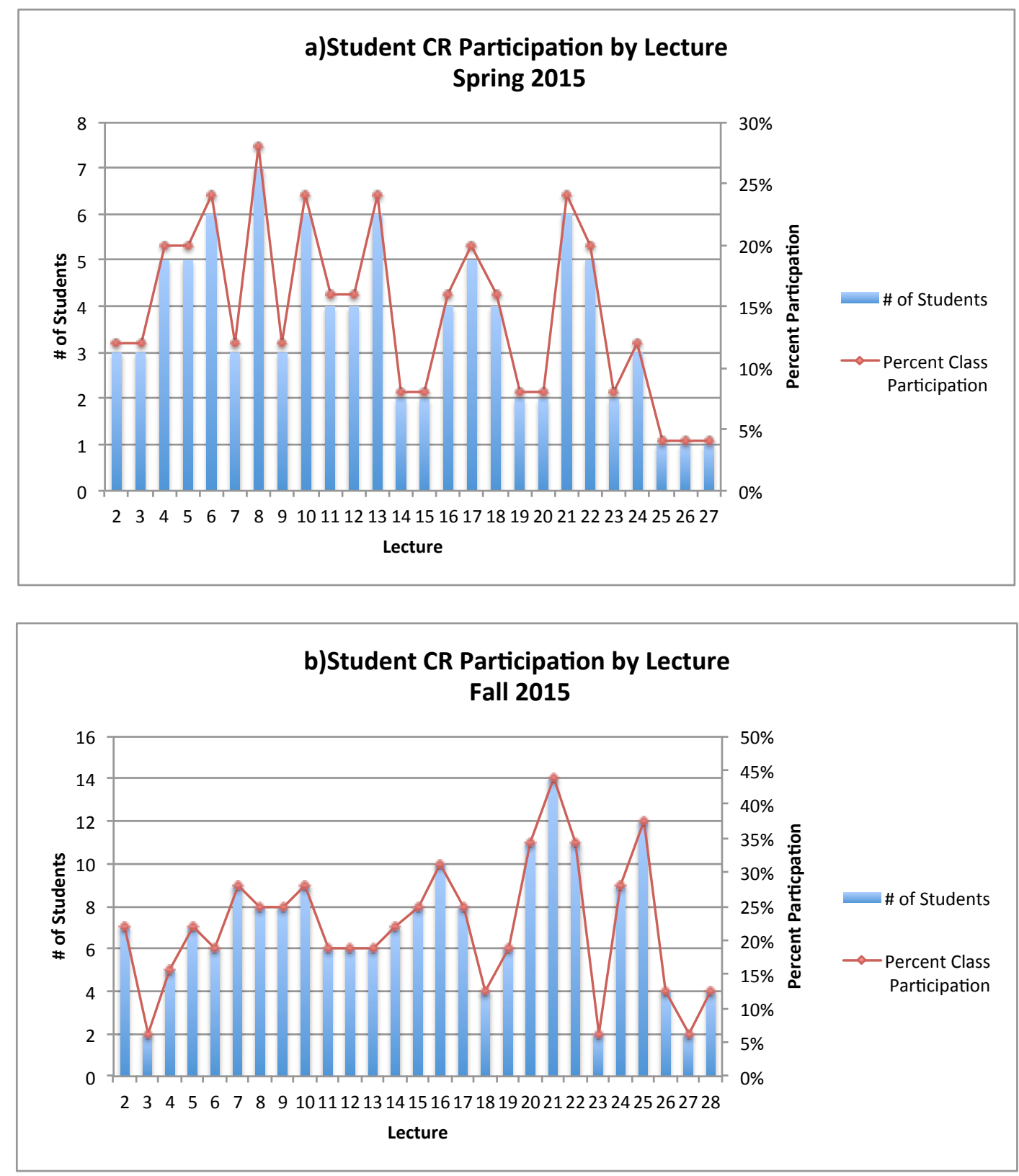

Figure 7-Number and percentage of students participating in CRs per lecture for (a) S15 and (b) F15. 
While the majority of the students in each class participate in CRs at some point in the semester, the number of students posting at least one CR for a given lecture is shown in Figure 7. As one can see, the number fluctuates. This is likely subject to a number of factors the students selfidentified, such as time availability, lecture topic confusion, stimulated interest by lecture topic, pre-arranged absence, and unforeseen sickness.

\section{Student-Selected Formats}

The breakdown of the five CR formats posted by students over the two semesters is shown in Figure 8. Far and away the most popular format is the YouTube video CR. To probe this, the students were asked to comment on why they do or do not use specific formats. Figure 9(a-b) shows the breakdown of how students decide their format and why they specifically choose videos to reflect on in their CRs. The most prevalent reasons students give for deciding their concept reflection format are (1) searching for concepts of interest and (2) always choose videos to help understand material. This implies that the videos help further their interest in the course content sparking curiosity and intrinsic motivation, as well as help clarify confusion they have self-identified in their learning process. An important parallel is noted between the students' selfselection of online videos to help understand the material and the students' overwhelming preference for instructor-generated videos as opposed to assigned readings or lecture notes for the method of flipped learning.

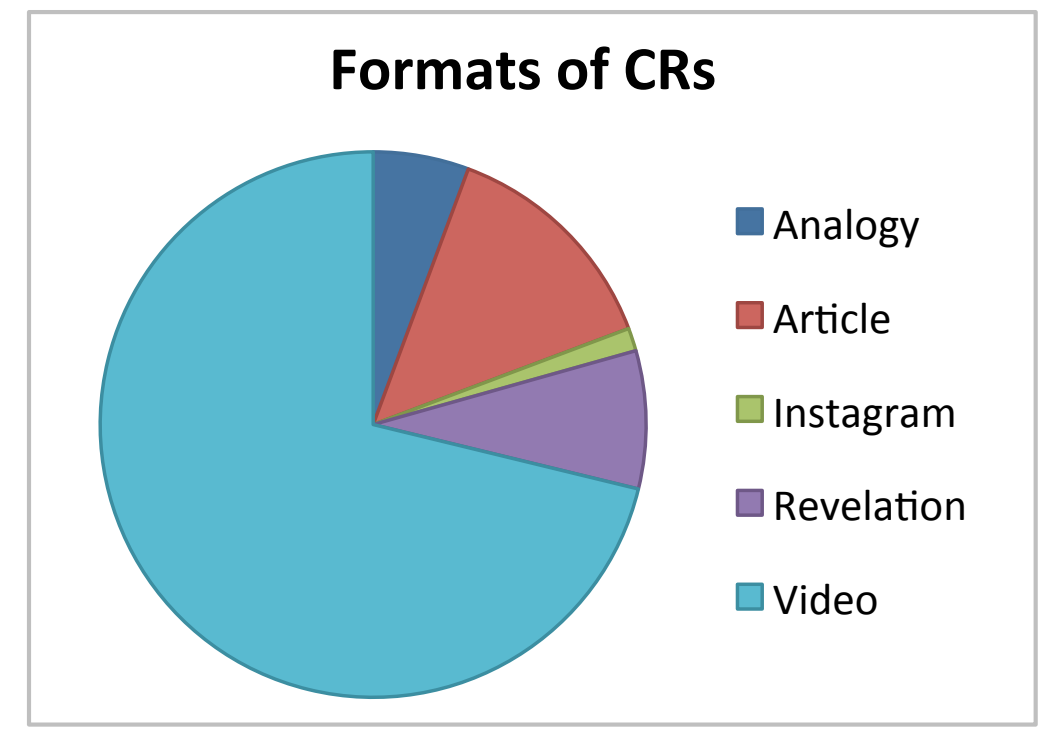

Figure 8 - Format of Concept Reflections Posted by Students. 

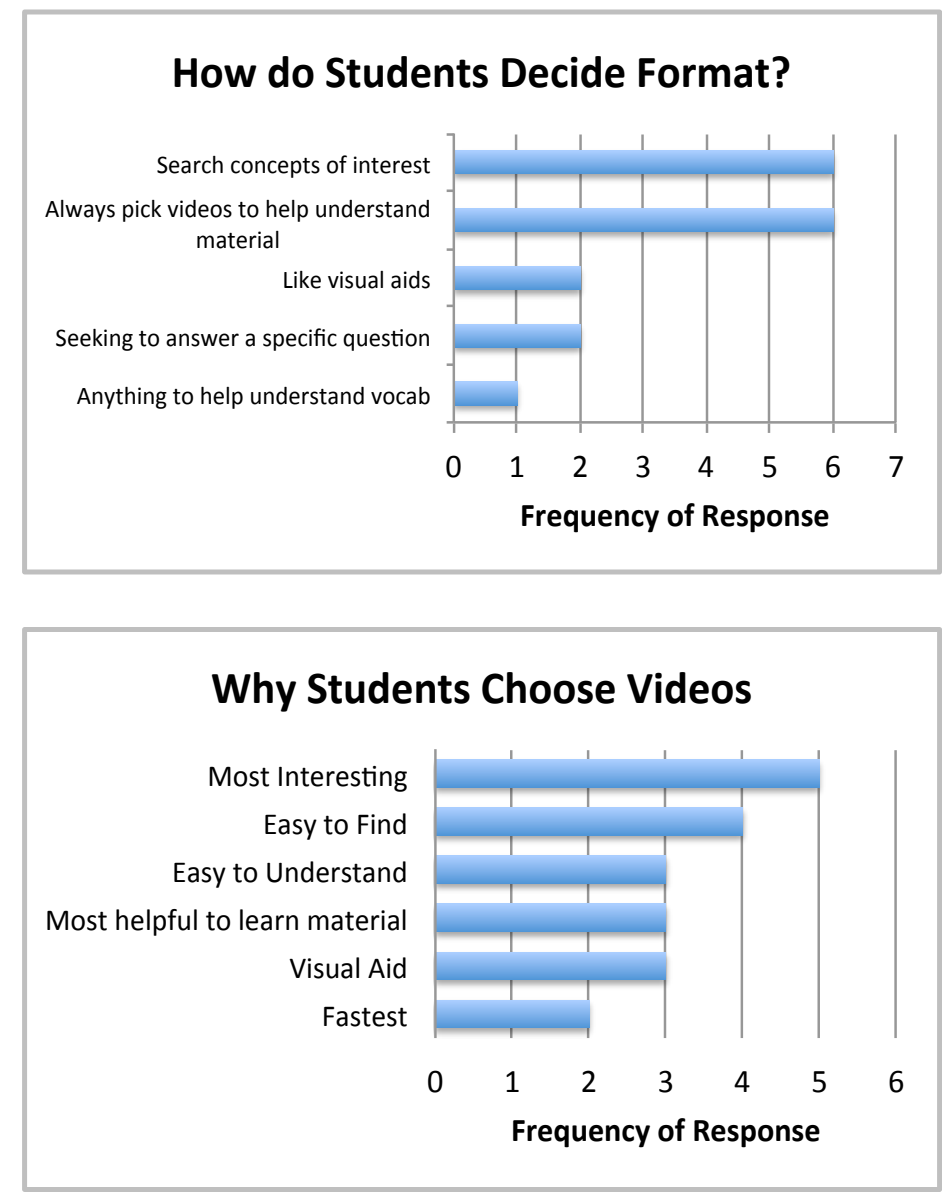

Figure 9 - Student survey results for (a) how students decide CR format, and (b) why students choose videos.

\section{Student Time Input}

Time input was an important aspect of the CRs that became apparent in student responses. To probe this, students were queried on the estimated amount of time that they spent on various aspects of completing a CR. This was broken down into the following three areas: deciding on the format and topic; searching for relevant information; and drafting the concept reflection text for the post. The total time spent on the CRs was then calculated by summing the highest number of minutes in each range the student selected (thus, termed the Maximum Total Time.)

The results, shown in Figure 10 (a-d), indicate that there is a wide variety of time input by the students to complete a CR. In general, the students spend the most time on the intermediate step of searching for the relevant information, while on average the total time that students spend on one concept reflection is 21-30 minutes.

In this way, students are spending additional time (beyond the lecture videos) focusing on an aspect of the course material in a self-selected direction. This can increase intrinsic motivation and curiosity towards the material, while at the very least this increases the student's mental time exposed to the course material before it is practiced more fully in lecture. This likely creates additional applications or experiences with the subject matter to help the student construct 
schemas related to the course content. Additionally, the time spent reflecting on the new information as they construct their CR post enacts a pivotal step in the learning process.
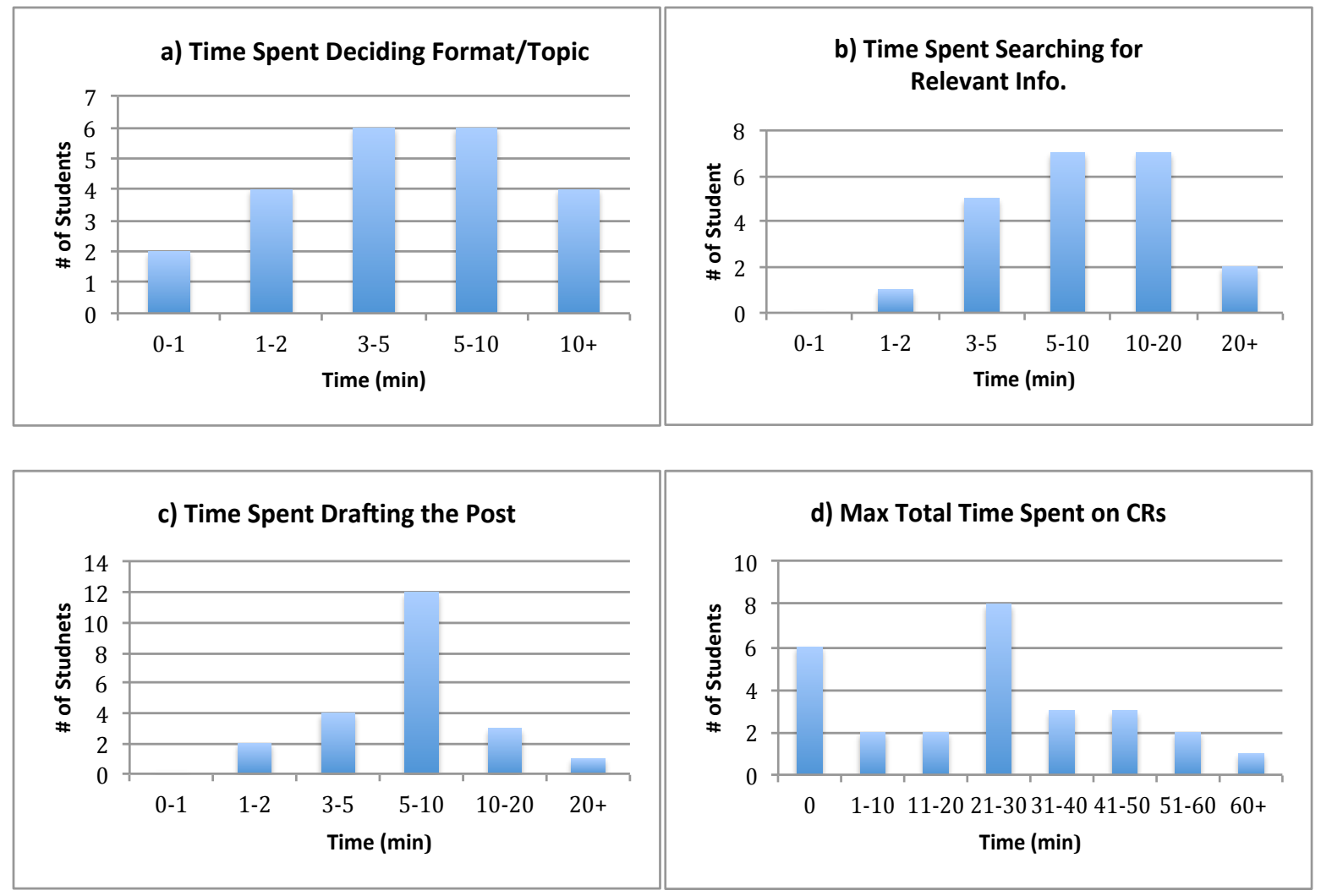

Figure 10 - Student survey results for time spent (a) deciding format/topic, (b) searching for relevant information, and (c) drafting the post, as well as (d) total compiled time spent on CRs.

\section{Student Submission Timing}

The timing breakdown of when students post their CRs before a given lecture is shown in Figure 11. Most of the students post the CRs in the morning before class time, while some post the day before. While procrastination may be blamed for this crunch of postings before class time, this may not be the whole story. Student comments in class indicated that students felt they did poorly on the quizzes when they watched the lecture videos too far ahead of class time. They found that watching the videos closer to class time was ideal. This makes sense for short-term memory arguments. If students did follow this model, then this compresses the time available to post CRs after watching the videos. This may help explain the data distribution that is seen in Figure 11. 

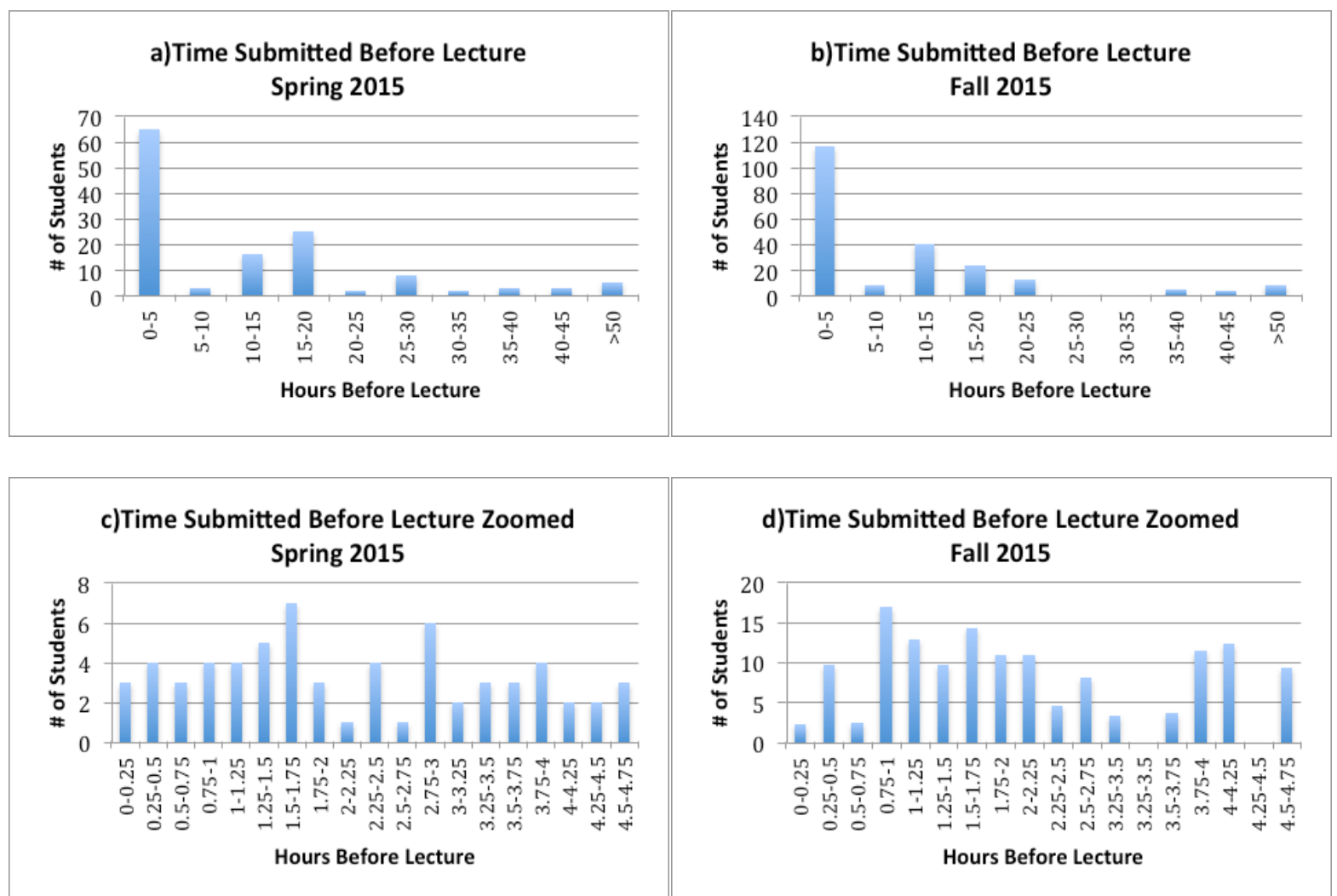

Figure 11 - Tabulated time of CR submissions before lecture. (a-b) Total time period leading up to lecture for $S 15$ and F15, respectively, and (c-d) zoom of last 5 hours before lecture for $S 15$ and F15, respectively. For reference, lecture start times: $S 15-1: 35 \mathrm{pm}$; F15-12:15pm.

\section{Effect on Student Quiz Performance}

It is difficult to directly assess the effect of the CRs on the students' performance due to their voluntary and stochastic participation. As noted previously, a majority of the class completed at least one CR over the course of the semester, though only a handful complete them for a given lecture. Thus, each lecture quiz must be taken individually to assess whether the students' completion of one or more CRs on that lecture material positively impacted their ability to perform on that quiz relative to their peers who did not complete a CR.

Figure 12 shows the deviation from the average scores (raw and compiled) for each student per lecture. The Raw Score is defined as the quiz score before accounting for any CR points, while the Compiled Score is the student's quiz score after adding in points for the completed CRs. Both the average raw score and average compiled score were calculated for each lecture. The deviations from the average score for that lecture were then computed for each student in the class. The students were finally classified by how many CRs they had completed for that lecture. Bins ranging from below to above the class average were created to categorize the results. Figure 12(a) shows that the students that complete CRs are generally slightly more likely to score higher than the class average on the quizzes. These results indicate that submitting a CR improves students memory and cognition of the material presented in the pre-class videos. Figure 12(b) shows that the students who have completed CRs almost always have a higher compiled score for that lecture than the class average. This is expected, since points are added to the compiled 
quiz score for completing CRs. These results correlate with the students' main motivations to complete CRs: to better understand or internalize the material (shown by the raw quiz scores), and to pad their quiz scores (shown by the compiled quiz scores.)

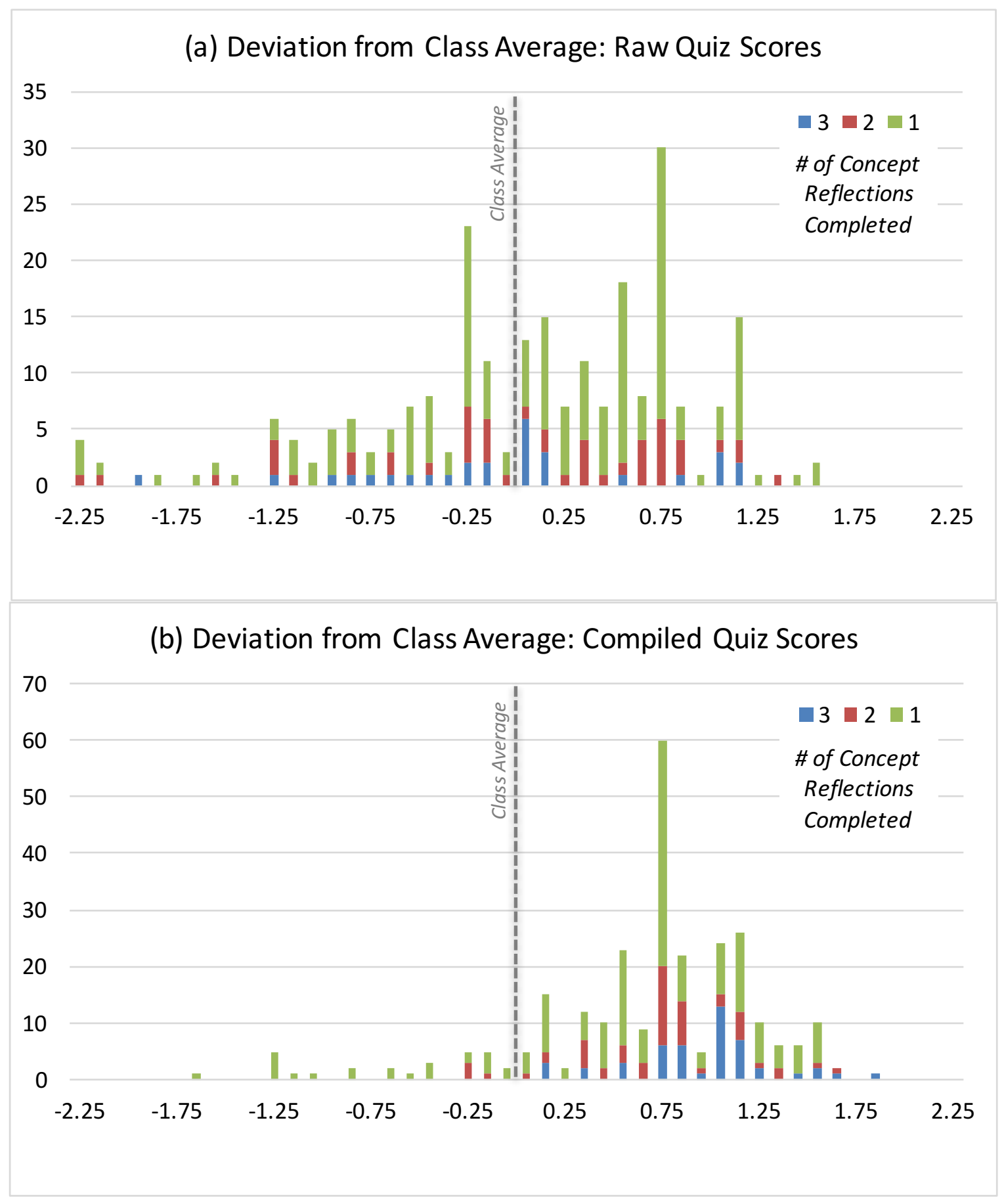

Figure 12 - Deviation from the class average (a) raw and (b) compiled score for each student for a given lecture for both semesters. See text for discussion of data analysis. 


\section{Dissemination of Concept Reflection Content}

Not only do CRs help the individual students who post them, but their content can also be disseminated to augment student understanding and content retention in current and future classes. Through reviewing the student-posted CRs, the instructor often discovers new applications, analogies, and media to demonstrate the course content. When possible, the best of these are then showcased during lecture to provide more examples for the students.

In the survey, students were queried about their use of the concept reflection information posted by other students. Multiple students mentioned that they like when the instructor mentions or shares student CRs during class time. Some students also commented that they sometimes look at fellow students' CR posts. One student wrote "What others post usually helps me understand material, too." However, in general, it appeared that there was not significant interaction between students with others' CRs beyond those specifically mentioned by the instructor in class.

\section{Instructor Time Input}

No doubt the review of multiple CRs for each lecture can be time-consuming for the instructor. This is particularly true as many of the CRs involve the viewing of YouTube videos in addition to reading the student's composed reflection. The instructor found that watching the videos at " $2 \mathrm{x}$ " speed saved much time in vetting the videos. Nevertheless, a technologically expedited grading strategy would definitely be an area of interest for future development.

\section{Discussion}

\section{Logistical Benefits}

Multiple challenges inherent to daily learning readiness quizzes are dramatically diminished when CRS are implemented as a complementary assessment mechanism. Firstly, student resentment for the instructor-imposed quizzes is markedly decreased as an avenue is opened for complete student-control of their own daily quiz grade. This additional avenue encourages student accountability to themselves (not the instructor) for their effort put into preparing for class. Secondly, giving students complete control of their quiz score outcome calms students with text anxiety. Thirdly, the CRs create a structure for how to deal with any missed quizzes, such as for absences, sickness, or even reoccurring time conflicts. The fact that the CRs are posted online and already familiar to the class means the instructor does not have to make up a new assessment method or grading rubric to deal with missed quizzes. Additionally, this requires that students still demonstrate a basic interaction with the lecture material, even if they were unable to attend that class period. This is a marked differentiation from grading structures where each student may drop a certain number of quizzes.

\section{Student Learning Benefits}

The CRs also have a number of benefits for student learning. First, the self-directed nature of student-generated CRs creates an open-ended learning environment that stimulates student motivation and curiosity about the subject matter. Students often indicate a desire to explore a 
certain subject or connect material to their personal lives in the written submission of CRs. The desire to further explore material is seen in the sample CRs provided above. In this way, the CRs leverage additional student-driven learning tools to internalize the subject matter, including the copious resources available via the Internet and the students' own interests and experiences.

Second, the CRs enhance cognition and memory of the subject matter. Long-term memory of information is built up by repeated attempts to retrieve the information, as well as how densely connected that information is to other information within the brain. Thus, the student-generated connections between the course content and their prior knowledge helps them better retain and understand what they are learning. This is seen as students who complete CRs consistently score higher than the average on quizzes. Moreover, the completion of each CR is extra time the student is spending searching for, thinking about, writing about, and reflecting upon a key aspect of the lecture prep material, increasing the probability that they will both remember and understand it.

Third, the CRs also develop metacognition and self-regulated learning within the students. By encouraging the students to identify their own topic of inquiry, the students practice a metacognitive understanding of what they do and do not understand. The survey given to students evaluating CRs revealed that many students choose to complete them in order to clarify confusing topics. This shows they are assessing their own understanding and self-regulating their learning. By having the students select their own method to investigate the concept, the students practice their metacognitive understanding of how they learn best (e.g. videos, articles, etc.) By making the CRs optional, the students must practice self-regulated learning, whereby they plan, monitor, and evaluate their progress in the class.

Finally, by having the students create new analogies and connections to the course content, the instructor reaps a plethora of examples to share with the class and future classes to aid understanding and retention of course concepts.

\section{Potential Improvements}

A number of potential improvements to the format and structure of CRs are discussed below.

\section{After-Class Posting Option}

If some of the central learning goals of CRs are to increase student time on topic and also increase student motivation towards the material, the instructor may consider allowing students to post CRs after class up until the next class period for a decreased point value. After the students know how well they do on the in-class quiz, they may be more motivated to complete a certain number of CRs. This increases the student's time on topic (perhaps especially needed if the student did not do well on the quiz), as well as allowing students to follow up on interesting topics or applications that were mentioned in class. The main drawbacks of such a scheme would be potentially decreased motivation to do CRs before class and the risk that students would be less prepared for both the quiz and class, knowing they could recoup any points they miss after the class period. Additionally, this added grading striation might complicate the quiz and CR grading. 


\section{Question Articulation}

Another potential change is to have students formulate a question for each CR that would motivate their search and include the question in their post. From the survey results, it appeared that some students may simply be internet searching for course content vocab in the hopes of stumbling upon further information. Forcing the students to articulate a question they have after watching the videos would help cultivate a habit of critical thinking and metacognition of their understanding of the content. Requiring students to title their post with a compelling question may also help attract other students to read the posts and disseminate the knowledge further.

\section{Student Posting Deadline}

Many students mentioned that they enjoyed when the instructor brought up the CRs during class; however, students often post their CRs just before class time, making it difficult for an instructor to review all of the CRs prior to class. To alleviate this, the instructor may consider a posting deadline 1-2 hours before class time, so that the instructor can review all the posts and mention them during class time. Downsides may be that many students watch the videos in the hours just before class (in order not to forget as much for quiz), so such a deadline may minimize the student's retention of material for class or decrease the number of students postings CRs.

\section{Grading Expedient}

One idea to ease the grading time input by the instructor is to somehow make the grading of CRs more technologically automated, akin to the electronic quiz grading. The instructor is currently investigating the potential of using coded word clouds of CRs to highlight the use of key words and adherence to required quality metrics, such as word count.

\section{Conclusions}

The main conclusions derived from the data in Figures 6-12 are summarized below:

- The greatest student motivators to do CRs are to pad their quiz score and to better understand the material.

- The greatest detractors are they don't have enough time or are already confident enough on the quizzes.

- While $79 \%$ of students complete at least one CR by the end of the course, only $10-20 \%$ of the class completes CRs for a given lecture.

- CRs based on YouTube Videos are the most common type completed. A wide variety of reasons are given by the students for this.

- There is a wide variety of time input by students on their CRs, but the average self-reported time was 21-30 minutes total for each CR.

- The majority of CRs are submitted in the last five hours before lecture.

- Students who completed CRs for a lecture were slightly more likely to do better than their peers on that in-class quiz (or RAT.) Once the CR points were added to their quiz scores, those students were virtually guaranteed to have a higher compiled quiz score for that lecture than the class average. 
In conclusion, CRs are a beneficial complement to instructor-generated RATs. Including them in the grading structure addresses a number of logistical hurdles, such as minimizing student resentment and anxiety towards the quizzes, and providing a mechanism to deal with student absences. The format of CRs also motivates key principles of student learning, including stimulating intrinsic motivation and curiosity, enhancing cognition and memory, and developing metacognition and self-regulation. This system of complementary readiness assessments allows for students with different learning styles to use whichever suits their learning more.

\footnotetext{
${ }^{1}$ Velegol, S. B., Zappe, S.E., and Mahoney, E. 2015. The Evolution of a Flipped Classroom: Evidence-Based Recommendations. Advances in Engineering Education 4(3):1-37.

${ }^{2}$ Leicht, R.M, Zappe, S.E., Messner, J. I. and Litzinger, T. 2012. Employing the Classroom Flip to Move "Lecture" Out of the Classroom. Journal of Applications and Practices in Engineering Education 3(1):19-31.

${ }^{3}$ Svinicki, M.D., and McKeachie, W.J.. 2014. McKeachie's Teaching Tips: Strategies, Research, and Theory for College and University Teachers. 14th ed. Wadsworth, Cengage Learning.

${ }^{4}$ Weinstein, S.E. and Wu, S.-W. 2009. Readiness Assessment Tests versus Frequent Quizzes: Student Preferences. International Journal of Teaching and Learning in Higher Education 21(2):181-186.

${ }^{5}$ Novak, G.N., Patterson, E.T., Gavrin, A., and Christian, W. 1999. Just-in-Time Teaching: Blending active Learning and Web Technology. Saddle River, NJ: Prentice Hall.

${ }^{6}$ Wilson, S.G. 2013. The Flipped Class: A Method to Address the Challenges of an Undergraduate Statistics Course. Teaching of Psychology 40(3):193-199.
} 